\title{
ESTIMATION OF OXIDATIVE STRESS IN TYPE 2 DIABETIC PATIENTS
}

\author{
Labani Ghosh¹, Indira Bhaskar Biswas², Nirmalya Roy³
}

${ }_{1}^{1}$ Postgraduate Student, Department of Biochemistry, K.P.C. Medical College \& Hospital, Kolkata.

2 Professor, Department of Biochemistry, K.P.C. Medical College \& Hospital, Kolkata.

${ }^{3}$ Associate Professor, Department of Medicine, K.P.C. Medical College \& Hospital, Kolkata.

\begin{abstract}
BACKGROUND

Poorly controlled blood glucose levels accelerate hyperglycaemia, induces excess free radical generation, and causes Oxidative stress. Thereby it is a condition of increased Oxidative stress and it requires antioxidants. The total antioxidants provide greater protection against damage caused by reactive oxygen species or reactive nitrogen species, than any single compound alone. Thus, overall antioxidant capacity may provide more relevant biological information compared to that obtained by the measurement of individual components.

Aims and Objectives- To evaluate whether Total Antioxidant Capacity and Malondialdehyde can be used for early screening of Oxidative Stress, and its correlation with HbA1c of both cases and controls.
\end{abstract}

\section{MATERIALS AND METHODS}

Study was conducted at a Tertiary Care Hospital. 50 T2DM patients were taken as cases of 40-60 age group, with 50 healthy subjects of similar age group. TAC, MDA and HbA1c of both cases and controls were assessed.

Statistical Analysis- Statistical Analysis done using SPSS 20 version software.

\section{RESULTS}

The mean HbA1c levels are higher in Cases $\{7.09 \pm 0.38\} \%$ than in Controls $\{4.55 \pm 0.41\} \%$ [p value $-<0.001$ ]. The mean TAC is decreased in Cases- $\{1.28 \pm 0.19\} \mathrm{mM}$ than in Controls- $\{2.3 \pm 0.18\} \mathrm{mM}$ [p value-<0.001], and an increase in MDA level is noted in Cases $\{2.11 \pm 0.34\}$ than in Controls $\{0.74 \pm 0.13\} \mathrm{nmol} / \mathrm{mL}$ [p value- $<0.001]$. A negative correlation of TAC of Cases $\{-0.959$, $\mathrm{p}$ value $-<0.001\}$ \& Controls $\{-0.991, \mathrm{p}$ value- $<0.001\}$ is noted, and a positive correlation of MDA of Cases $\{0.624, \mathrm{p}$ value $-<0.001\} \&$ Controls $\{0.936$, $p$ value- 0.001$\}$ are noted with respect to HbA1c.

\section{CONCLUSION}

The above assays could be employed to detect complications early and revert the conditions to a certain extent. This would increase the longevity and quality of life of patients with diabetes.

\section{KEYWORDS}

Total Antioxidant Capacity, Malondialdehyde, Type 2 Diabetes Mellitus, Oxidative Stress.

HOW TO CITE THIS ARTICLE: Ghosh L, Biswas IB, Roy N. Estimation of oxidative stress in type 2 diabetic patients. J. Evolution Med. Dent. Sci. 2017;6(22):1758-1762, DOI: $10.14260 / \mathrm{Jemds} / 2017 / 387$

\begin{abstract}
BACKGROUND
Type 2 diabetes mellitus (T2DM) has reached global epidemic proportions, ${ }^{1}$ and certain population subgroups are vulnerable to the disease. The incidence of type 2 diabetes mellitus (T2DM) is increasing rapidly, a figure that will soon make the disease one of the world's most prevalent causes of preventable mortality. As per the International Diabetes Federation (IDF), the estimated cases of diabetes in India in the age group of $20-70$ years were 6.68 crore and 6.91 crore in 2014 and 2015 respectively. The number of people with diabetes is expected to rise to 642 million by $2040 .^{2}$ Diabetes mellitus is characterised by chronic hyperglycaemia with disturbances of carbohydrate, fat and protein metabolism resulting from the defects in insulin secretion, or insulin action or both. ${ }^{3}$
\end{abstract}

Financial or Other, Competing Interest: None.

Submission 03-02-2017, Peer Review 04-03-2017,

Acceptance 09-03-2017, Published 16-03-2017.

Corresponding Author:

Dr. Labani Ghosh,

$\# A / 1$, Subal Koley Lane,

Howrah-711101.

E-mail:drlabani22@gmail.com

DOI: $10.14260 /$ jemds $/ 2017 / 387$

\section{Concept of Oxidative Stress}

Chronic hyperglycaemia results in the generation of free radicals due to increased production of mitochondrial ROS (Reactive Oxygen Species) by non-enzymatic glycation of proteins and glucose autoxidation. Elevated Free fatty acid can also result in oxidative stress due to increased mitochondrial uncoupling and oxidation leading to the increased production of ROS. In addition to an increase in free radical, a decrease in antioxidant capacity occurs in diabetes mellitus. In the absence of an appropriate compensatory response from the endogenous antioxidant network, the system becomes overwhelmed (Redox imbalance), leading to the activation of stress-sensitive intracellular signalling pathways leading to the production of gene products that causes cellular damage and are ultimately responsible for the late complications of diabetes. $4,5,6$

\section{Generation of Free Radical}

Formation of ROS and RNS (Reactive nitrogen species) can occur in the cells by two ways: enzymatic and non-enzymatic reactions. Enzymatic reactions generating free radicals include those involved in the respiratory chain, the phagocytosis, the prostaglandin synthesis and the cytochrome P450 system. Non-enzymatic reactions of oxygen 
with organic compounds as well as those initiated by ionising radiations. The non-enzymatic process can also occur during oxidative phosphorylation (i.e. aerobic respiration) in the mitochondria. ROS and RNS are also generated from either endogenous or exogenous sources. Endogenous free radicals are generated from immune cell activation, inflammation, mental stress, excessive exercise, ischaemia, infection, cancer, ageing. Exogenous ROS/RNS result from air and water pollution, cigarette smoke, alcohol, heavy or transition metals ( $\mathrm{Cd}, \mathrm{Hg}, \mathrm{Pb}, \mathrm{Fe}, \mathrm{As}$ ), certain drugs (Cyclosporine, tacrolimus, gentamycin, bleomycin), industrial solvents, cooking (Smoked meat, used oil, fat), radiation. After penetration into the body by different routes, these exogenous compounds are decomposed or metabolised into free radicals. $7,8,9$

\section{Oxidative Stress \& Type 2 Diabetes Mellitus}

Oxidative stress plays a pivotal role in the development of diabetes complications, both microvascular and cardiovascular. The metabolic abnormalities of diabetes cause mitochondrial superoxide overproduction in endothelial cells of both large and small vessels, as well as in the myocardium. This increased superoxide production causes the activation of 5 major pathways involved in the pathogenesis of complications: polyol pathway flux, increased formation of AGEs (Advanced glycation end products), increased expression of the receptor for AGEs and its activating ligands, activation of protein kinase $\mathrm{C}$ isoforms, and over-activity of the hexosamine pathway. Through these pathways, increased intracellular reactive oxygen species (ROS) cause defective angiogenesis in response to ischaemia, activate a number of pro-inflammatory pathways, and cause long lasting epigenetic changes that drive persistent expression of pro-inflammatory genes after glycaemia is normalised. Thereby atherosclerosis and cardiomyopathy in type 2 diabetes are caused in part by pathway- selective insulin resistance, mitochondrial ROS production from free fatty acids and by inactivation of anti-atherosclerotic enzymes by ROS. 10

\section{MATERIALS \& METHODS}

The study was carried out at the outpatient clinic of Department of Medicine, patients were chosen \& all the biochemical studies \& investigations were carried out in Department of Biochemistry, in a Tertiary Care Hospital, Kolkata. Our study group consists of 50 Type 2 Diabetic patient Cases of age ranging from 40-60 yrs. \& 50 Controls of the similar age group.

The Case \& Control subjects were randomly selected with age \& sex matched. The Case subjects age ranging from 40-60 years, fitted the inclusion criteria of type 2 diabetes. The case subjects were on oral hypoglycaemic drugs and were not on any kind of oral antioxidants. The exact duration of type 2 diabetes according to the history given by the Case subjects themselves were around 6-7 years. The Control subjects were healthy patients aged (40 - 60 years) with no history of T2DM or antioxidant supplements, and they were included in the "Healthy criteria". With proper understanding, the subjects have accepted to undergo this procedure and have accordingly given their consent.

\section{Inclusion criteria of Case subjects}

HbA1c or Glycated haemoglobin $\geq 6.5 \%$.

OR

Fasting Plasma Glucose $>126 \mathrm{mg} / \mathrm{dL}$.

OR

Postprandial Plasma glucose $>200 \mathrm{mg} / \mathrm{dL}$ after oral glucose intake. The test was to be performed as described by the World Health Organisation after a glucose load containing the equivalent of $75 \mathrm{~g}$ anhydrous glucose dissolved in water OR Random plasma glucose $>200 \mathrm{mg} / \mathrm{dL}$.

\section{Inclusion Criteria for Control Group}

- Fasting Plasma glucose $<100 \mathrm{mg} / \mathrm{dL}$.

- 2-hour Plasma glucose level $<140 \mathrm{~g} / \mathrm{dL}$.

- $\operatorname{HbA} 1 \mathrm{c} \leq 5.7 \%$.

\section{Exclusion Criteria for Case \& Control}

- History of alcohol consumption.

- History of severe renal, hepatic \& neurological disease.

- Pregnant women.

- Individuals refusing to provide informed consent.

- History of hypertensive crisis.

- History of known cardiovascular disorders.

- Not on any kind of Antioxidant supplementations.

Venous blood samples from all the participants were drawn after an overnight fast from an antecubital vein into clotted and EDTA tubes. Serum was separated and retained for analysis of TAC, MDA and HbA1c respectively.

\section{Methodology}

Total Antioxidant Capacity (TAC)

By Colorimetric assay (BioVision Assay kit, total antioxidant capacity assay Kit, K274-100).11

\section{Malondialdehyde (MDA)}

It was evaluated by the Thiobarbituric Acid test. ${ }^{12}$

\section{Glycated Haemoglobin (HbA1c)}

It was evaluated by HPLC (Bio-Rad- D10). ${ }^{13}$

\section{RESULTS}

We have included 100 subjects in our study, where 50 were type 2 DM subjects \& 50 were healthy individuals. The patients were from the Tertiary Care Hospital situated in Kolkata, West Bengal. Data analysis were done using SPSS 20 version software.

The mean HbA1c level is higher in Cases $\{7.09 \pm 0.38\} \%$ than in Controls $\{4.55 \pm 0.41\} \%$ [p value- $<0.001]$ which is given in Table 1, Figure 1. The mean TAC level is decreased in Cases $\{1.28 \pm 0.19\} \mathrm{mM}$ than in Controls $\{2.3 \pm 0.18\} \mathrm{mM}[\mathrm{p}$ value- $<0.001]$ which is given in Table 2; Figure 2 . The mean MDA level is increased in Cases $\{2.11 \pm 0.34\} \mathrm{nmol} / \mathrm{mL}$ than in Controls $\{0.74 \pm 0.13\} \mathrm{nmol} / \mathrm{mL}$ [p value- $<0.001]$ which is shown in Table 3, Figure 3. A negative correlation of TAC with HbA1c of both Cases $\{-0.959$, p value- $<0.001\}$ \& Controls $\{-$ 0.991 , p value $-<0.001\}$ and is shown in Table $4[a, b]$, Figure $4 \mathrm{a}, 4 \mathrm{~b}$ respectively. There is a positive correlation of MDA with $\mathrm{HbA} 1 \mathrm{c}$ of both Cases $\{0.624$, p value $-<0.001\}$ \& Controls $\{0.936, \mathrm{p}$ value- 0.001$\}$ and it is shown in Table 5 [a, b], Figure $5 \mathrm{a}, 5 \mathrm{~b}$ respectively. 


\begin{tabular}{|c|c|c|l|l|}
\hline \multirow{4}{*}{} & \multicolumn{2}{|c|}{ Group } & & \\
\cline { 2 - 5 } & Case & Control & & \\
\cline { 2 - 5 } & $\begin{array}{c}\text { Mean } \pm \text { Std. } \\
\text { Deviation }\end{array}$ & $\begin{array}{c}\text { Mean } \pm \text { Std. } \\
\text { Deviation }\end{array}$ & p Value & Significance \\
\hline HbA1c $\%$ & $7.09 \pm 0.38$ & $4.55 \pm 0.41$ & $<0.001$ & Significant \\
\hline \multicolumn{3}{|c|}{ Table 1. Comparision of HbA1c of Case \& Control } \\
\hline
\end{tabular}

\begin{tabular}{|c|c|c|c|c|}
\hline \multirow{4}{*}{} & \multicolumn{2}{|c|}{ Group } & & \\
\cline { 2 - 5 } & Case & Control & & \\
\cline { 2 - 5 } & $\begin{array}{c}\text { Mean } \pm \text { Std. } \\
\text { Deviation }\end{array}$ & $\begin{array}{c}\text { Mean } \pm \text { Std. } \\
\text { Deviation }\end{array}$ & p Value & Significance \\
\hline TAC mM & $1.28 \pm 0.19$ & $2.3 \pm 0.18$ & $<0.001$ & Significant \\
\hline \multicolumn{4}{|c|}{ Table 2. Comparision of TAC of Case \& Control } \\
\hline
\end{tabular}

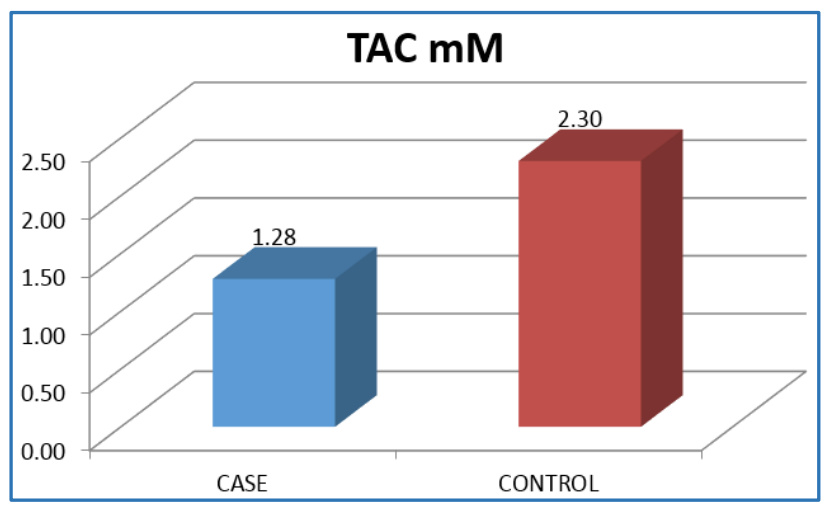

Figure 2

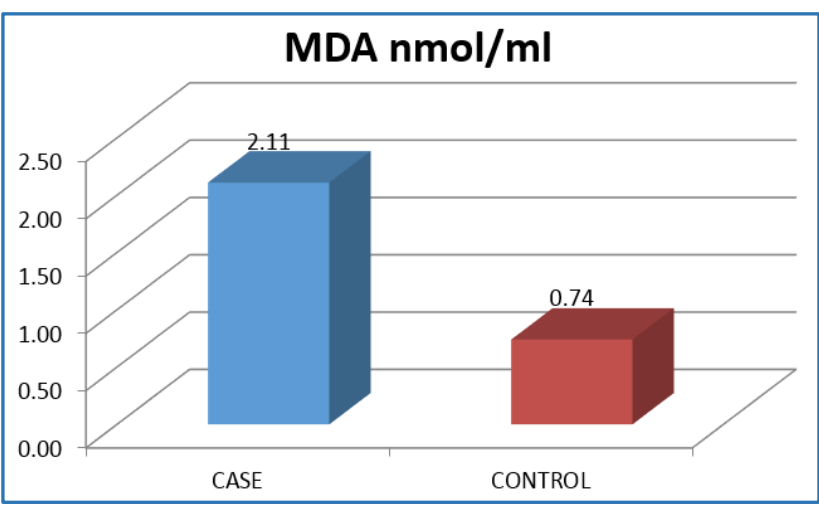

Figure 3

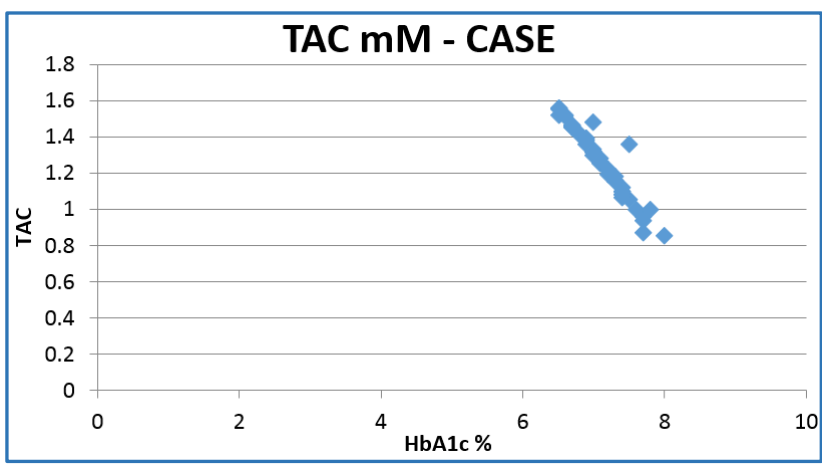

Figure 4a. Case

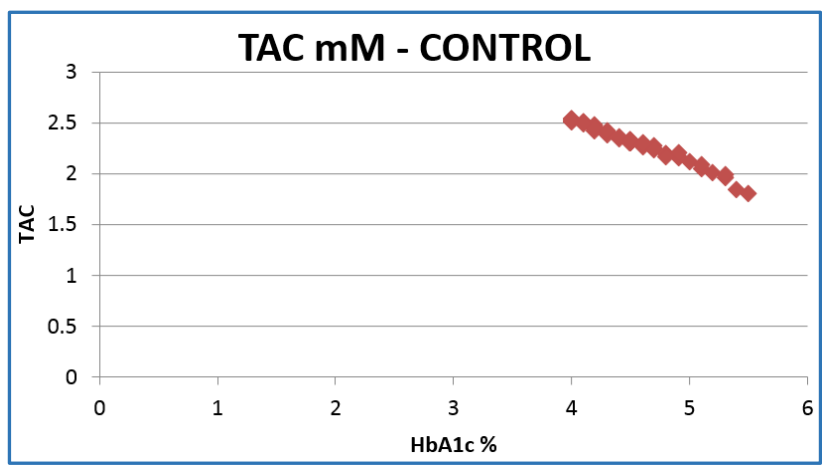

Figure 4 b. Control

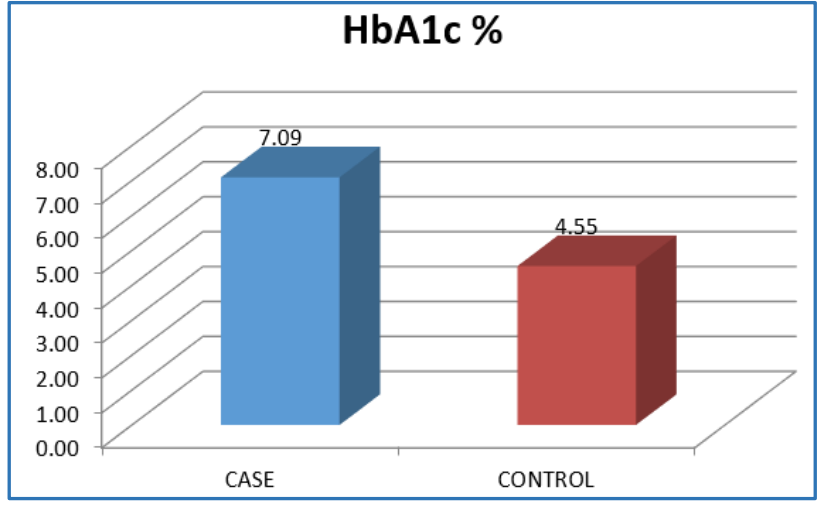

Figure 1 


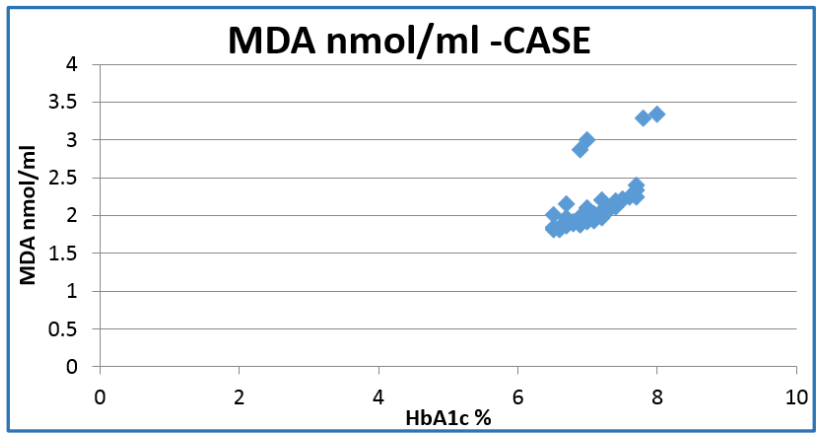

Figure 5 a. Case

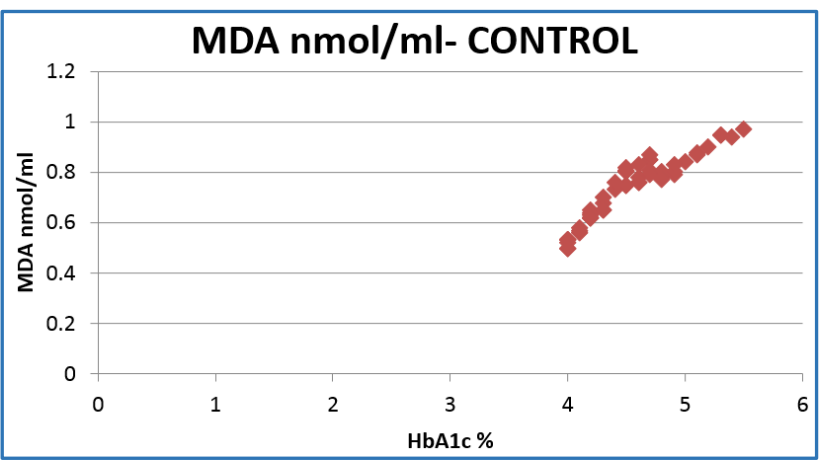

Figure 5 b. Control

\section{DISCUSSION}

Type 2 diabetes mellitus is a disease which has a tendency to progress into a state of various complication, oxidative stress, heightened inflammatory process and eventually leading to metabolic dysregulation. Countries with the highest number of diabetics are in India (19 million), China (16 million), and the United States (14 million). ${ }^{14}$ In our study, parameters of oxidative stress of 50 middle-aged subjects with age ranging from 40-60 years, along with healthy subjects (Control group) with age \& gender matched, were evaluated with a detailed assessment of history \& is included in the study according to the inclusion criteria already discussed in materials \& methods, and statistical analysis is done.

The mean glycated haemoglobin (HbA1c) is increased in Case group when compared with the Control group and has been found statistically significant.

Results are consistent with the study done by Kodiatte et al, Verma et al \& Masram et al where Kodiatte et al,15 Masram et al ${ }^{16}$ \& Verma et al ${ }^{17}$ stated HbA1c was increased in type 2 diabetic subjects compared to control group.

As of present scenario, hyperglycaemia appears as a significant cornerstone, providing a favourable cellular environment for increased RONS (Reactive oxygen \& nitrogen species) production and successively leading to increased production of free radicals and impaired antioxidant defences resulting in increased oxidative stress (OS) contributing to the development and progression of diabetes and its complications. Thereby Total Antioxidant Capacity (TAC) is being assessed as an "antioxidant marker" \& Malondialdehyde (MDA) as a marker for elevated lipid damage.

In our study, the mean TAC levels is decreased \& MDA levels is increased in type 2 diabetic subjects when compared to the control group and this has been found statistically significant.
Results are consistent with a study done by Manohar et al,18 Eldin et al, ${ }^{19}$ Hisalkar et al, ${ }^{20}$ Opara et al, ${ }^{21}$ Bandeira et $\mathrm{al}^{22}$ Girona et $\mathrm{al}^{23}$ Salinas et $\mathrm{al}^{24}$ where they stated that there was a decrease in TAC \& increase in MDA level type 2 diabetic participants when compared.

We observed that chronic hyperglycaemia influences the generation of free radicals, which eventually leads to increased lipid peroxidation and depletion of antioxidants, and thereby enhancing oxidative stress in subjects with T2DM.

Glycaemic control is the most important aspect in management of diabetes mellitus, thereby it has become a cornerstone in reducing morbidity and mortality of the diseases. $^{25}$ The measurement of HbA1c level is the gold standard for assessment of glycaemic control because the concentration of $\mathrm{HbA1c}$ predicts diabetic complications as it reflects harmful glycation sequelae of diabetes, such as retinopathy and nephropathy, which are understood to be due to harmful advanced glycation end products. ${ }^{26,27}$

A negative correlation is noted in our study when glycated haemoglobin (HbA1c) is correlated with TAC in Cases when compared to that of Controls. Results are consistent with the study done by Song et al, where they stated a negative correlation with TAC in respect to HbA1c. ${ }^{28}$

Decreased antioxidant activity (TAC) is observed in patients with Type 2 diabetes, which is possibly associated with the progressive glycation of the enzymatic protein caused by high HbA1c levels in the patients. 29,30,31

A positive correlation is noted with MDA of Case, \& that of Control and has been found statistically significant.

Results are consistent with the study done by Song et al, where they stated a positive correlation with $\mathrm{HbA1c}$ in the presence of hyperglycaemia. ${ }^{29}$

\section{CONCLUSION}

Type 2 DM is strongly associated with various risk factors, that have the ability to proceed to a complicated state, which eventually cause the patients to lead a burdened compromised life.

In our study, we focused on ruling out the panel of test for screening of type 2 diabetic subjects who are at early risk of developing complication.

In our study, it has been found that there is a significant decrease in evaluated Oxidative stress (TAC) in T2DM Case subjects when compared with the Control group, showing that excessive free radical generation has been initiated due to the incompetency of "antioxidant defence system".

A negative correlation is also noted of TAC in respect to $\mathrm{HbA1c}$, stating that due to increase in HbA1c there is a decrease in "Total Antioxidant Capacity".

In our study, there is an increase in MDA, in type 2 diabetic subjects when compared to Control group, and has been positively correlated with $\mathrm{HbA1c}$, stating an increased lipid peroxidation in diabetic subjects which is due to associated dyslipidaemia.

Thereby, these panel of tests can be considered for screening of the target population for the oxidative stress along with routine check-up, and with proper interventions, it can slow the process to a certain extent by improving the quality and longevity of life of the patient with T2DM. 
However, additional further studies with larger patient populations are needed to replicate the results of this study.

\section{REFERENCES}

[1] Wild S, Roglic G, Green A, et al. Global prevalence of diabetes: estimates for the year 2000 and projection for 2030. Diabetes Care 2004;27(5):1047-53.

[2] International Diabetes Federation. IDF diabetes atlas seventh edition: 2015. Brussels, Belgium: 2015 [updated 2015; cited 2016 Aug 16]. Available from: http://www.idf.org/diabetesatlas/update-2015.

[3] Bennett PH, Knowler WC. Definition, diagnosis, and classification of diabetes mellitus \& glucose homeostasis. In: Kahn CR, Weir GC, King GL, et al. (eds) Joslin's diabetes mellitus. 14th edn. New Delhi, India. Wolters Kluwer (India) Pvt. Ltd 2005, Indian Reprint 2011.

[4] Maxwell SR, Thomason H, Sandler D, et al. Antioxidant status in patients with uncomplicated insulindependent and non-insulin dependent diabetes mellitus. Eur J Clin Invest 1997;27(6):484-90.

[5] Salonen JT, Nyyssonen K, Tuomainen TP, et al. Increased risk of non-insulin dependent diabetes mellitus at low plasma vitamin E concentrations: a four year follow up study in men. BMJ 1995;311(7013):1124-7.

[6] Shigeta Y, Hiraizumi G, Wada M, et al. Study on the serum level of thioctic acid in patients with various diseases. J Vitaminol (Kyoto) 1961;7:48-52.

[7] Valko M, Leibfritz D, Moncol J, et al. Free radicals and antioxidants in normal physiological functions and human disease. Review Int J Biochem Cell Biol 2007;39(1):44-84.

[8] Valko M, Izakovic M, Mazur M, et al. Role of oxygen radicals in DNA damage and cancer incidence. Mol Cell Biochem 2004;266(1-2):37-56.

[9] Halliwell B. Biochemistry of oxidative stress. Biochem Soc Trans 2007;35(Pt 5):1147-50.

[10] Brownlee M. The pathobiology of diabetic complications: a unifying mechanism. Diabetes 2005;54(6):1615-25.

[11] Nishikawa T, Edelstein D, Du XL, et al. Normalizing mitochondrial superoxide production blocks three pathways of hyperglycaemic damage. Nature 2000;404(6779):787-90.

[12] Janero DR. Malondialdehyde and thiobarbituric acidreactivity as diagnostic indices of lipid peroxidation and peroxidative tissue injury. Free Radic Biol Med 1990;9(6):515-40.

[13] Davis JE, McDonald JM, Jarett L. A high-performance liquid chromatography method for hemoglobin A1c. Diabetes 1978;27(2):102-7.

[14] Mahsud MAJ, Khan A, Hussain J. Hematological changes in tobacco using type 2 diabetic patients. Gomal J Med Sci 2010;8(1):8-11.

[15] Kodiatte TA, Manikyam UK, Rao SB, et al. Mean platelet volume in type 2 diabetes mellitus. Journal of Laboratory Physician 2012;4(1):5-9.

[16] Masram SW, Bimanpalli MV, Ghangle S. Study of lipid profile and glycated hemoglobin in diabetes mellitus. Indian Medical Gazette 2012;145(7):257-65.
[17] Verma M, Paneri S, Badi P, et al. Effect of increasing duration of diabetes mellitus type 2 on glycated haemoglobin and insulin sensitivity. Indian Journal of Clinical Biochemistry 2006;21(1):142-6.

[18] Manohar SM, Vaikasuvu SR, Deepthi K, et al. An association of hyperglycemia with plasma malondialdehyde and atherogenic lipid risk factors in newly diagnosed type 2 diabetic patients. J Res Med Sci 2013;18(2):89-93.

[19] Eldin EEMN, Almarzouki A, Assiri AM, et al. Oxidized low density lipoprotein and total antioxidant capacity in type-2 diabetic and impaired glucose tolerance Saudi men. Diabetology \& Metabolic Syndrome 2014;6(1):94.

[20] Hisalkar PJ, Patne AB, Karnik AC, et al. Ferric reducing ability of plasma with lipid peroxidation in type 2 diabetes. JPBS 2012;2(2):53-6.

[21] Opara EC, Abdel-Rahman E, Soliman S, et al. Depletion of total antioxidant capacity in type 2 diabetes. Metabolism 1999;48(11):1414-7.

[22] de Bandeira SM, José LS, da Fonseca, et al. Oxidative stress as an underlying contributor in the development of chronic complications in diabetes mellitus. Int J Mol Sci 2013;14(2):3265-84.

[23] Girona J, Manzanares JM, Marimóm F, et al. Oxidized to non-oxidized lipoprotein ratios are association with metabolic syndrome in diabetic patients. NMCD 2008;18(5):380-7.

[24] Calderón-Salinas JV, Muñoz-Reyes EG, GuerreroRomero JF, et al. Eryptosis and oxidative damage in type 2 diabetic mellitus patients with chronic kidney disease. Mol Cell Biochem 2011;357(1-2):171-9.

[25] American Diabetes Association. Standards of medical care in diabetes 2014. Diabetes Care 2014;37(Suppl 1):S14-80.

[26] Weykamp C, John GW, Mosca A. A review of the challenge in measuring hemoglobin A1c. Journal of diabetes Sci Technol 2009;3(3):439-45.

[27] Pasupathi P, Manivannan P, Uma M, et al. Glycated haemoglobin (HbA1c) as a stable indicator of type 2 diabetes. Int J Pharm Biomed Res 2010;1(2):53-6.

[28] Song F, Jia W, Yao Y, et al. Oxidative stress, antioxidant status and DNA damage in patients with impaired glucose regulation and newly diagnosed type 2 diabetes. Clinical Science 2007;112(12):599-606.

[29] Bhatia S, Shukla R, Madhu VS, et al. Antioxidant status, lipid peroxidation and nitric oxide end products in patients of type 2 diabetes mellitus with nephropathy. Clin Biochem 2003;36(7):557-62.

[30] Komosinska-Vassev K, Olczyk K, Olczyk P, et al. Effects of metabolic control and vascular complications on indices of oxidative stress in type 2 diabetic patients. Diabetes Res Clin Pract 2005;68(3):207-16.

[31] Saha A, Adak S, Chowdhury S, et al. Enhanced oxygen releasing capacity and oxidative stress in diabetes mellitus and diabetes mellitus-associated cardiovascular disease: a comparative study. Clinical Chimica Acta 2005;361(1-2):141-9. 